Int. J. Dev. Biol. 61: 137-148 (2017)

doi: $10.1387 / \mathrm{ijdb} .160270 \mathrm{hc}$

\title{
Annotating the genome by DNA methylation
}

\author{
HOWARD CEDAR* and AHARON RAZIN \\ Department of Developmental Biology \& Cancer Research. Faculty of Medicine, Hebrew University of Jerusalem, \\ Jerusalem, Israel
}

\begin{abstract}
DNA methylation plays a prominent role in setting up and stabilizing the molecular design of gene regulation and by understanding this process one gains profound insight into the underlying biology of mammals. In this article, we trace the discoveries that provided the foundations of this field, starting with the mapping of methyl groups in the genome and the experiments that helped clarify how methylation patterns are maintained through cell division. We then address the basic relationship between methyl groups and gene repression, as well as the molecular rules involved in controlling this process during development in vivo. Finally, we describe ongoing work aimed at defining the role of this modification in disease and deciphering how it may serve as a mechanism for sensing the environment.
\end{abstract}

KEY WORDS: DNA methylation, chromatin, epigenetics, gene regulation, repression

\section{Introduction}

It is now well accepted that there is a sophisticated chemical system to annotate the genetic text and in this way regulate the way genes are read and interpreted in each cell. Nonetheless, in the early seventies very little was known about how the animal genome is controlled. The elegant work of Jacob and Monod had paved the way for understanding the fundamental idea of how cis-acting elements and trans-acting factors control transcription in bacteria, but animal cells appeared to have complex patterns of gene expression which could not easily be explained on the basis of this principle alone.

Early studies indicated that the DNA in animal cells is not free in solution, but rather packaged within an ordered protein structure made up of well-defined histones and this served to compress the genetic material (Felsenfeld, 1978). Using RNA polymerase to probe this structure, it was demonstrated that individual genes are available for transcription in chromatin from the cell type of expression, while being closed in other tissues (Axel et al., 1973; Cedar and Felsenfeld, 1973). This was confirmed by similar experiments using nucleases to probe for regions that are open to digestion (Weintraub and Groudine, 1976; Panet and Cedar, 1977). These studies helped establish a brand new concept that pictured the 3D-genome map as being mostly inaccessible to the transcription machinery while specific loci were available for factor interactions. It thus appeared that chromatin structure may play a big role in gene regulation.

\section{Methylation and expression}

It was always assumed that the genetic text is identical in every cell of the body, having been derived directly from the parental gametes. It had already been shown in the 1940's, however, that at least one pyrimidine base, Cytosine, was often found to be methylated in animal DNA, although literally nothing was known about its distribution. Understanding the overall structure of chromatin allowed us, for the first time, to probe the possible relevance of DNA methylation to gene expression. In a very simple experiment using micrococcal nuclease digestion to isolate core nucleosomal DNA, we demonstrated that this protected fraction is relatively methylated compared to open regions (Razin and Cedar, 1977; Solage and Cedar, 1978). This indicated that DNA methylation is not distributed evenly across the genome, representing the first hint that this modification may be correlated with gene repression.

By employing restriction enzymes to measure DNA methylation levels at specific sites in the genome, it was demonstrated that a number of individual genes are preferentially unmethylated in their tissue of expression while being highly modified in other cell types (van der Ploeg and Flavell, 1980). In our laboratory, we used DNasel to carry out nick translation on chromatin, thereby selectively labeling active regions of the genome, which were then shown to be preferentially hypomethylated (Fig. 1). This was then confirmed

Abbreviations used in this paper: HBB, $\beta$ globin; IE, island element; Po, polyp.

\footnotetext{
*Address correspondence to: Howard Cedar. Dept. Developmental Biology \& Cancer Research, Faculty of Medicine, Hebrew University, P.O.B. 12272 Ein Kerem, Jerusalem 91120 Israel. Fax: 972-2-641-5848 .Tel: 972-2-675-8167. E-mail: cedar@ mail.huji.ac.il - web: http://haimcedar.ekmd.huji.ac.il
}

Accepted: 10 August, 2016.

ISSN: Online 1696-3547, Print 0214-6282 

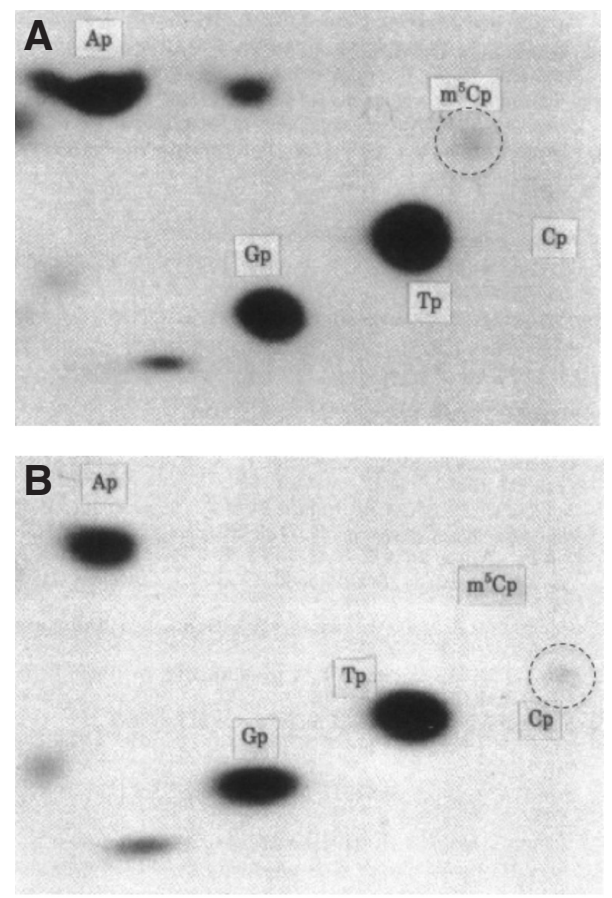

Fig. 1. Active DNA is undermethylated. Nearest neighbor analysis shows the distribution of all nucleotides (A, G, T and C) located near $G$ in total DNA (A). Over $75 \%$ of the CpG dinucleotide is methylated. In contrast, specifically labeled (by nick translation) active DNA (B) has mostly unmethylated $\mathrm{CpGs}$. This indicates that active regions of the genome are undermethylated. Adapted from Naveh-Many and Cedar (1981).

by isolating DNA complementary to the total mRNA population, which again was found to be undermethylated compared to the rest of the genome (NavehMany and Cedar, 1981). Taken together these studies demonstrated that DNA methylation is correlated with repression, strongly suggesting that it may actually play a role in the control of transcription.

\section{DNA methylation patterns}

The observation that some sites in a given cell population are consistently methylated while others are unmethylated strongly suggested that there are fixed patterns of modification that are maintained in dividing cells. In order to prove this concept, we adopted the newly invented technology of DNA mediated gene transfer (transfection) (Wigler et al., 1977). Bacterially-cloned DNA inserted into animal cells becomes integrated into the genome and remains completely unmethylated. In contrast, when this same DNA was first methylated in vitro using the Hpall methylase (CCGG), these specific sites retained their modified state regardless of the underlying sequence, even many cell generations later (Pollack et al., 1980; Stein etal., 1982a). This seminal experiment demonstrated that DNA methylation patterns are not generated de novo in somatic cells, and are not necessarily directed by transacting factors, but once formed, can be faithfully maintained in dividing cells.

These transfection studies strongly implied that there must be an autonomous mechanism for preserving methylation patterns, one that is not dependent on sequence. It had been suggested that DNA methylation may actually be "copied" during replication in a manner similar to the sequence text itself, perhaps by utilizing DNA methyltransferases found in the nucleus (Razin and Riggs, 1980). This idea was consistent with the observation that all methyl groups in animal-cell DNA are located at CpG sites and are therefore symmetrically placed on both strands (Cedar et al., 1979). To test this concept, we extracted methylase activity from animal cells and used this to methylate various forms of DNA in vitro. Strikingly, this enzyme was found to preferentially modify a hemi-methylated substrate with specificity over 100 -fold greater than completely unmethylated DNA (Gruenbaum et al., 1982) (Fig. 2).

This experiment suggested that during replication, synthesis of the new strand would automatically generate a hemi-methylated site which would then be recognized by the DNA methyltransferases that would fill in a methyl group opposite that of the native DNA. In contrast, unmethylated $\mathrm{CpG}$ residues would not be recognized by this enzyme. In this way, the methylation pattern present in the mother cell would be faithfully copied to the daughter cells in an autonomous manner. The foundation for this mechanism is the dinucleotide symmetry of $\mathrm{CpG}$ residues that enable the methylation on one strand to serve as a template for methylating the second strand using Dnmt1 together with additional protein factors (Bostick et al., 2007).

Support for this concept also came from our studies on methylation in plant DNA. Nearest-neighbor experiments indicated that as opposed to animal DNA, methylation in plants was observed at additional non-symmetric C-containing dinucleotides, including $\mathrm{CpC}, \mathrm{CpA}$ and CpT. While this initial observation did not appear to be compatible with a maintenance mechanism, extended analysis revealed that all of these methylations were actually associated with the more general sequence family, CXG, containing a trinucleotide symmetry (Gruenbaum et al., 1981) and subsequent experiments later showed that plants indeed contain enzymes capable of recognizing hemi-methylated DNA at these sites, thus providing the machinery for autonomous maintenance in plant cells. Taken together, these experiments provide the basis for understanding

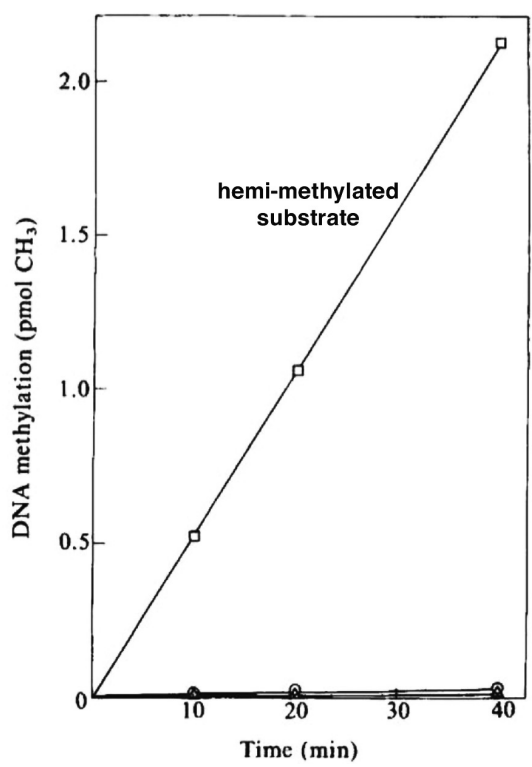

Fig. 2. Specificity of methylase for hemi-methylated DNA. DNA methylase activity was extracted from cells and used on unmethylated DNA $(\triangle)$, methylated DNA (O) or a hemi-methylated DNA substrate ( $\square)$. This experiment explains how maintenance methylation works. Adapted from (Gruenbaum et al., 1982). 


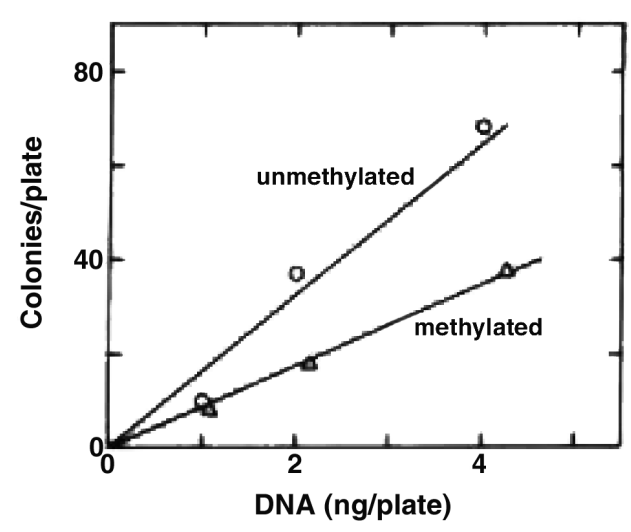

Fig. 3. Methylation inhibits gene expression. Transfection efficiency of an unmethylated $(O)$ or methylated $(\triangle)$ tk gene at various concentrations into $L t k^{-}$cells in culture, with selection for $t^{+}$. Note that methylation inhibits tk gene activity. Adapted from (Pollack et al., 1980).

how DNA methylation patterns are maintained through replication, thereby serving as an efficient memory mechanism.

\section{DNA methylation represses gene expression}

All of the initial studies on DNA methylation indicated a good correlation between gene expression and undermethylation, suggesting, but not proving, that the presence of methylation may operate to inhibit transcription. We designed experiments to actually test this hypothesis using DNA-mediated gene transfer. We stably introduced the HSV tk gene into mouse L-cells in culture and then compared this to the same tk gene that had been methylated in vitro using the Hpall methylase, which modifies all CCGG sites (Pollack et al., 1980). Strikingly, the methylated gene was much less active (Fig. 3 ) and similar results were obtained for a variety of different co-transfected genes. Since in this experiment the only difference between the two templates was their in-vitro added methylation, it was clear that it must be the methyl groups themselves that repress gene activity. Housekeeping genes that are normally unmethylated in almost all cells were inhibited (Stein et al., 1982b) as well as tissue-specific genes, such as $\beta$-globin (Yisraeli et al., 1988). Since the endogenous $\beta$-globin gene in these mouse cells is in a methylated state, this experiment suggested indirectly that normal tissue-specific genes of this nature are probably repressed in most cells by virtue of their methylation.

While these studies had shown that the presence of DNA methylation inhibits transcription, it was not clear how this might be carried out. Considering that expression, in general, appeared to be controlled by accessibility, we did a simple experiment to test whether DNA methylation itself may affect chromatin structure. To this end, we stably inserted bacterial DNA into animal cells and measured its sensitivity to DNasel once it had integrated in the endogenous chromosomal material. As expected, this DNA was shown to be sensitive to nucleases. In contrast, when this same DNA was first methylated in vitro, it still integrated into the DNA, but in a form that was resistant to DNasel treatment (Keshet et al., 1986) (Fig. 4), and became wrapped in nucleosomes carrying deacetylated histones, another indication of inactive DNA (Eden et al., 1998). This effect was exclusively dependent on DNA methylation itself and occurred despite the fact that these were foreign templates carrying no eukaryotic regulatory sequences, and taken together, these results clearly showed that DNA methylation plays a role in controlling chromatin structure and gene accessibility.

\section{DNA methylation in development}

After having derived the basic rules of DNA methylation, we next turned our attention to understanding how DNA methylation patterns are established during development. Studies in the 80s indicated that in the very early embryo the general levels of DNA methylation were low, but these experiments did not give information about specific gene sequences (Monk et al., 1987). The main problem was that a more sensitive assay was needed to measure DNA methylation in samples with extremely low cell numbers. With this in mind, we developed a method for carrying out methylationsensitive restriction enzyme analysis in combination with PCR to amplify the DNA. Our results showed that many different gene sequences originally methylated in oocyte and sperm DNA appear to undergo a slow process of erasure in the preimplantation embryo (Kafri etal., 1992). These sequences ultimately become methylated again at about the time of implantation, while $\mathrm{CpG}$ islands remain unmethylated throughout this entire process. These studies demonstrated that DNA methylation apparently undergoes a process of reprogramming, whereby methylation marks present in the gametes are removed and a new pattern then generated in each individual (Fig. 5). This made it clear that methylation patterns are not inherited from parents, and thus represent an epigenetic, as opposed to a genetic mark. More recent studies using high throughput bisulfite sequencing analysis have confirmed these results both in mouse and in man (Smith et al., 2012; Smith et al., 2014).

The studies on DNA methylation patterns during early embryogenesis indicated that implantation is accompanied by a wave of de novo methylation that appears to modify many sites, but leaves $\mathrm{CpG}$ islands unmethylated. Since this was clearly a major defining step in the generation of methylation profiles, we sought to understand how this worked. To this end, we developed an in vitro system employing ES cells. Although these cells initially appeared to be derived from the blastula, in terms of DNA methylation, they

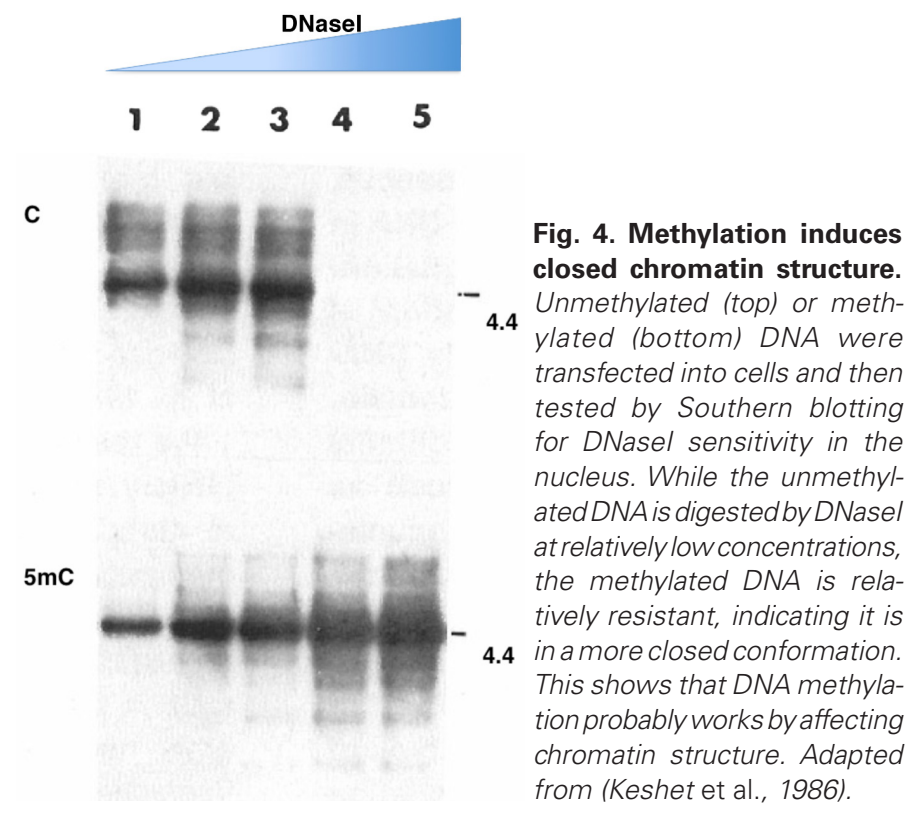


Fig. 5. Programming of DNA methylation patterns during development. Almost all methylation in the gametes is erased (yellow) in the preimplantation embryo, but imprinting centers retain methylation on one allele (black). At the time of implantation, the entire genome gets methylated (blue), but the $\mathrm{CpG}$ islands are protected (yellow circles). Postimplantation, pluripotency genes are de novo methylated (black). Tissue-specific genes undergo demethylation lorange in Tissue 1, pink in Tissue 2) in their cell type of expression. Imprinting centers remain differentially methylated throughout development. Somatic cell reprogramming by induced pluripotent stem cells or fusion resets the methylation pattern of somatic cells to the stage of implantation. See (Cedar and Bergman, 2012)
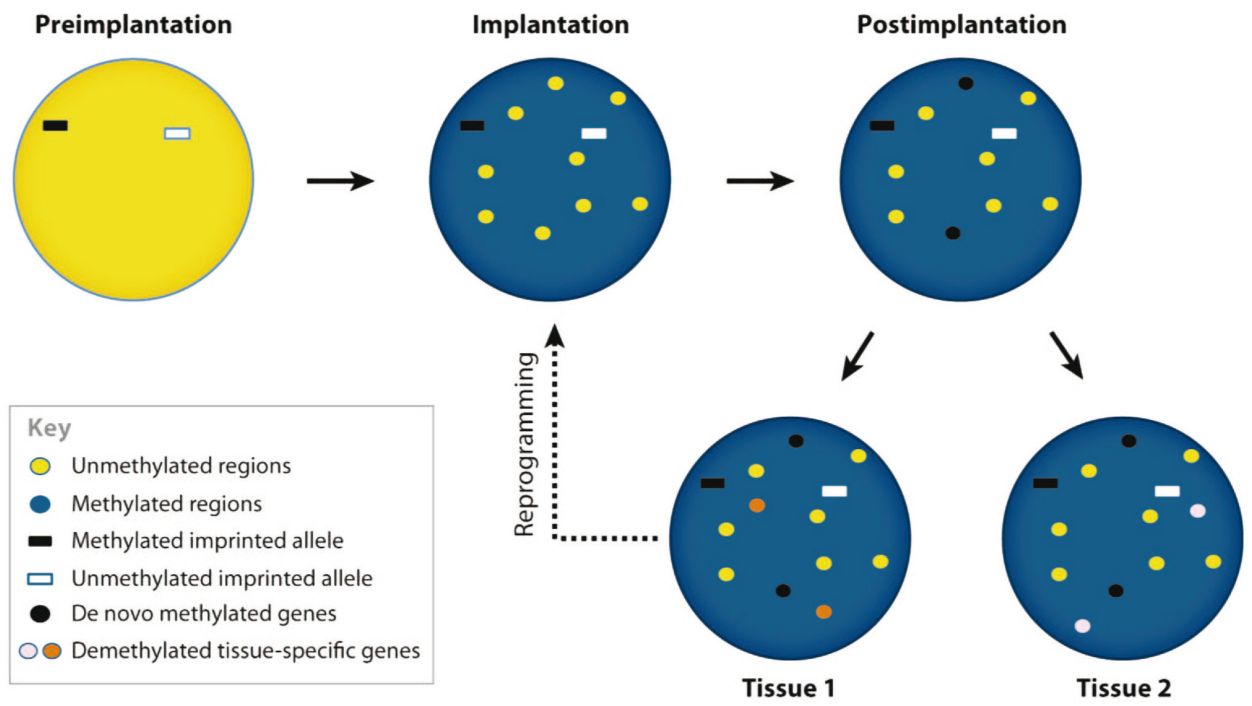

turned out to be an excellent model for the implantation stage of embryogenesis. Using transfection, we demonstrated that all DNA inserted into these cells becomes de novo methylated, a result that is strikingly different than what happens in somatic cells where there is very little de novo activity. Strikingly, when $\mathrm{CpG}$ island DNA was inserted into these cells, no methylation took place, exactly mimicking what happens at the time of implantation (Frank et al., 1991; Brandeis et al., 1994).

In vivo, CpG islands are literally protected from the de novo methylation that takes place at the time of implantation, and this occurs without any need for demethylation. In contrast, ES cells have a unique ability to recognize and demethylate $\mathrm{CpG}$ islands in a reaction that apparently utilizes a defined molecular complex that contains all the components needed to remove methyl groups (Sabag et al., 2014). It is very likely that this mechanism, which is not involved in the molding of $\mathrm{CpG}$ islands during normal development, actually plays an important role in the ability of ES cells to reprogram somatic nuclei by demethylating all those $\mathrm{CpG}$ islands that underwent de novo methylation during differentiation and

Preimplantation
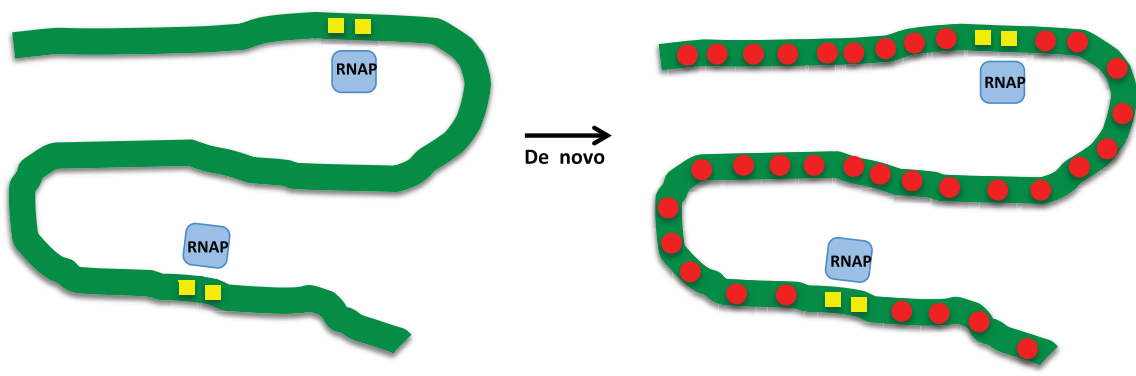

Fig. 6. Establishment of a bimodal methylation pattern. Preimplantation, the genome is largely unmethylated. Cis acting sequences (yellow squares) in $\mathrm{CpG}$ islands serve as binding sites for RNA polymerase. At the time of implantation there is a wave of de novo methylation (red circles) that modifies all CpG sites in the genome while regions marked with RNA polymerase binding are protected. This pattern is then maintained through every cell division even if RNA polymerase is no longer bound to the islands. According to this model, de novo DNA methylation does not bring about repression of active genes, but can serve to perpetuate the repression of genes originally inactive in the preimplantation embryo. aging, thus resetting the global methylation pattern to its original bimodal state.

\section{Cis acting sequences control DNA methylation}

This ES-cell system also enabled us to evaluate what specific sequence elements are involved in molding the bimodal methylation profile at the time of implantation. To our surprise, it turned out that the high concentration of $\mathrm{CpG}$ is not the direct signal for protection of islands. Instead, it appears that it is the recognition of simple cis-acting sequences at these loci, and the transcription factor Sp1 binding-motif, for example, is sufficient to drive this reaction (Brandeis et al., 1994). Indeed, even using this sequence alone it was possible to make any piece of DNA resistant to de novo methylation and this was then proven in vivo by its ability to control the methylation state in transgenic mice (Siegfried and Cedar, 1997). Using bioinformatics to analyze the sequence composition of all constitutively unmethylated CpG islands in the genome, it was possible to write an algorithm that predicts with high accuracy which regions of the DNA will remain unmodified at the time of implantation (Straussman et al., 2009). This mathematical formulation clearly implies that the pattern of methylation is actually directed by sequence elements in the DNA.

Interestingly, an overall look at the sites protected from de novo methylation suggests that the selection of these regions is based on their association with RNA polymerase. Not only are these loci enriched for many transcription factor binding sites, but mapping experiments even indicate that these regions generally serve as gene promoters and literally all of them contain histones that are methylated at $\mathrm{H} 3 \mathrm{~K} 4$, another clear-cut sign of transcriptional potential. These results suggest that $\mathrm{CpG}$ islands are already marked at transcription start sites in the preimplantation embryo and that this serves as the mechanism for protection from de novo methylation at the time of implantation (Fig. 6). Although appearing counterintuitive, these results actually demonstrate that 


$\begin{array}{llll} & \operatorname{lox} P & \operatorname{lox} P & \\ \text { puc19 } & \mathrm{IE} & \text { HBB }\end{array}$



Fig. 7. Cis-acting sequences protect $\mathbf{C p G}$ islands. A human $\beta$ globin (HBB) transgenic animal containing an island element (IE), which protects against de novo methylation, flanked by loxP sites was crossed with a mouse which expresses cre constitutively. Since the IE is removed preimplantation, the HBB sequence gets de novo methylated in vivo. When crossed with an inducible Cre (Mx-Cre), however, the IE is still present at implantation and this protects against de novo methylation. If $M x$-cre is induced in the adult, the IE is removed, but this does not affect methylation. This experiment demonstrates that cis acting sequences control $C p G$ island protection from de novo methylation and also shows that once the methylation pattern is formed at implantation, it is maintained, even in the absence of the original cis acting sequences (IE). de novo methylation does not itself bring about repression, but rather serves to mark and then perpetuate the inactive state by making it difficult to turn on these genes in the soma.

By understanding the sequence code that controls DNA methylation patterns, it then became possible to finally test in a conclusive manner whether DNA methylation has a real function in vivo. To this end, we constructed a $120 \mathrm{bp}$ island-inducing sequence element (IE) flanked by LoxP sites, embedded it within the human $\beta$-globin gene and generated a mouse transgene (Siegfried and Cedar, 1997). Using Cre to remove the "island sequence" prior to implantation, we showed that the transgene gets de novo methylated and remains that way in all tissues. In contrast, if the IE is not removed, the genomic region behaves like a CpG island and is protected from de novo methylation. In these mice, Cre-induced removal of the IE in the adult has no effect on DNA methylation. These studies clearly showed that the overall methylation pattern is indeed established as a one-time event in the early embryo and is then maintained autonomously even though the cis-acting sequences that drive this specificity at the time of implantation are no longer present (Fig. 7). When tissues from these mice were analyzed for gene expression, we found that the presence of DNA methylation caused anywhere from a 20-50 fold reduction of RNA synthesis, clearly substantiating the claim that DNA methylation represses gene transcription in vivo. In addition, methylation also had a big effect on chromatin structure in vivo, mainly by affecting histone acetylation (Hashimshony et al., 2003).

\section{Genomic imprinting}

Genomic imprinting is a phenomenon whereby some genes are expressed from only a single parental genome, either the maternal or paternal. Obviously, this implies that there must be a mechanism by which these sites remember where they come from, and it was hypothesized that these genes were differentially methylated in the gametes and then retained these patterns throughout development. Indeed, methylation analysis confirmed that this is indeed the case and through the use of methylase knockouts, it was shown that this modification is required for imprinting (Li et al., 1993). We realized that in order for this model to work, these imprinting marks had to be preserved during early embryogenesis at a time when the entire genome methylation pattern was undergoing erasure (Fig. 5).

Using the sensitive PCR assays that we had developed, we demonstrated that these marks are established at the end of gametogenesis and are then maintained in a monoallelic manner in the pre-implantation embryo (Brandeis et al., 1993; Kafri et al., 1993; Stoger et al., 1993). We also showed that these marks are

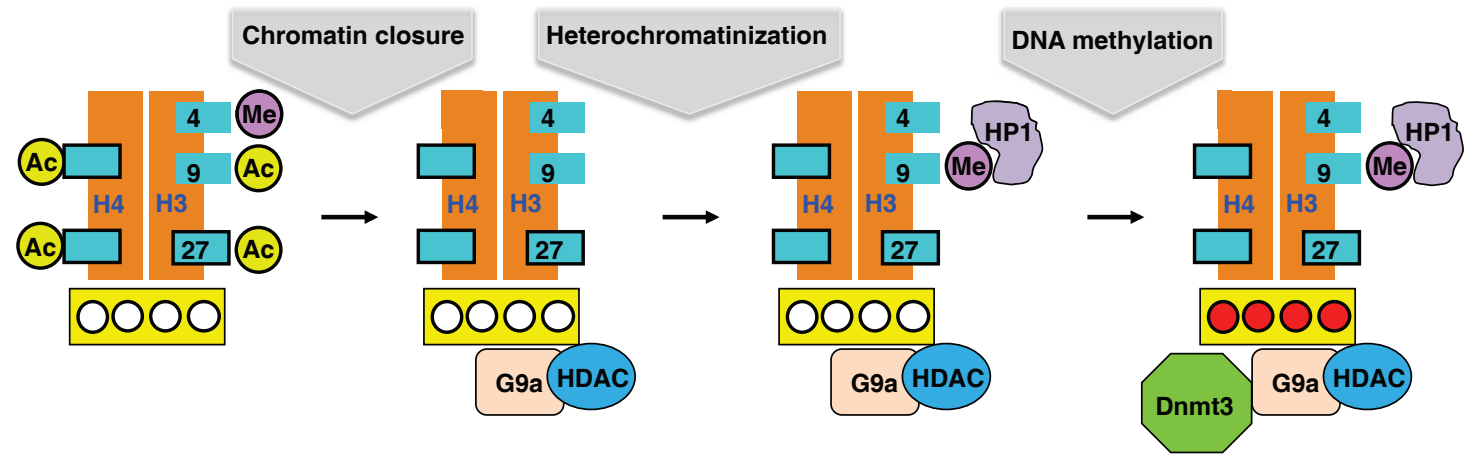

Fig. 8. Epigenetic inactivation of pluripotency genes. Pluripotency gene promoters are unmethylated (white ovals) and carry nucleosomes with acetylated histones and H3K4me3. Differentiation brings about gene repression in 3 steps. 1) transcriptional repression, 2) heterochromatinization through the action of G9a which recruits HDACs together with histone H3K4 demethylases and then methylates H3K9 which serves as a binding site for heterochromatin protein -1 (HP1) and 3) G9a recruits Dnmt3 which methylates (red ovals) the DNA. Adapted from Cedar and Bergman (2012). 
erased during early gametogenesis in the next generation only to be reset in the mature gamete, thus completing the imprinting cycle. In order to better understand this process, we developed a zygote injection method for testing the maintenance mechanism, and, in this way, discovered that this protection required specific cis-acting control sequences (Birger et al., 1999), and this ultimately led to the idea of an imprinting control region (ICR) which turns out to be the master regulator of the entire process (Shemer et al., 2000; Perk et al., 2002).

\section{The basic bimodal methylation pattern}

Putting all of these studies together, DNA methylation emerges as a global repression mechanism. Erasure in the early embryo serves to reprogram the epigenetic information present in the gametes and then, using sequence cues from the genome, a new methylation pattern is established which can subsequently be maintained in every cell of the body. This serves to set up an expression template which is programmed to allow housekeeping genes with CpG island promoters to be unmethylated and "open" while other regions of the genome and many tissue-specific regulatory elements are modified and "closed," thus preventing their inadvertent expression in somatic cells.

In order to prove this point, we took a close look at the $\gamma$ globin gene that is normally methylated in every cell of the body except for the fetal liver where it is expressed. Using targeting technology, we converted the promoter of this gene to a CpG island-like sequence, causing it to be unmethylated in every cell type (Goren et al., 2006). Strikingly, this gene now undergoes abnormal transcription in almost every tissue. In adult $\beta$-globin expressing red

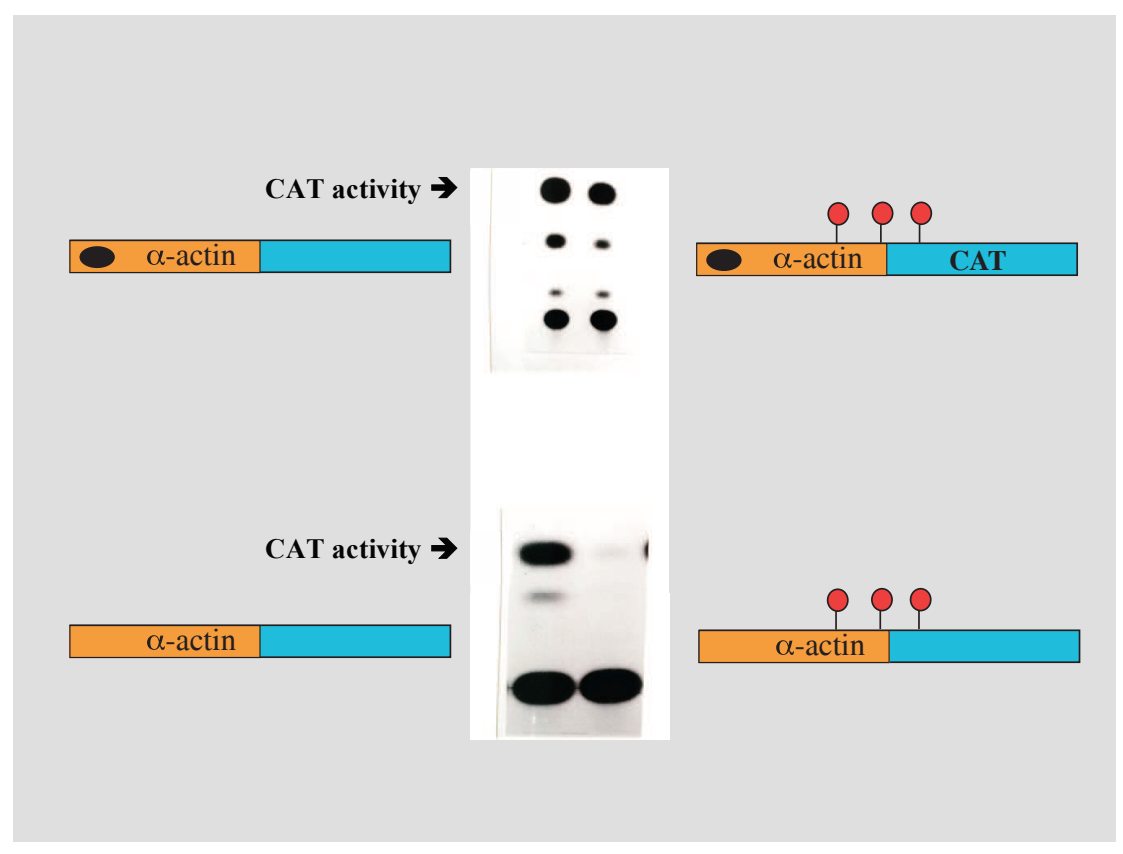

Fig. 9. Tissue-specific demethylation. An $\alpha$-actin reporter construct transfected into myoblasts showed CAT activity (using chromatography to detect the product), whether it was methylated or not (top panel). This is because the gene has a regulatory region (black dot) which causes demethylation in myoblasts. If the regulatory region is deleted, the methylation cannot be removed and the gene remains inactive. This demonstrates that tissue-specific demethylation is controlled by cis acting regulatory sequences and that methylation must be removed for the gene to be active. blood cells where this gene is usually methylated and inactive, the unmethylated $\gamma$ globin gene is expressed at high levels, presumably aided by the rich abundance of globin-type transcription factors present in these cells. This example provides a much clearer picture for how global methylation operates in vivo to suppress genes by preventing inadvertent activation by a variety of different transcription factors present in somatic cells. It should be noted that the overall strategy used in animal cells differs markedly from the system present in simpler organisms where gene-specific repressors modulate gene activity. In the animal-cell system, a very large number of genes are silenced in each cell type and this is controlled by a global mechanism that does not require that each gene be recognized by a specific repressor.

\section{Post implantation}

In keeping with our goal of understanding the role DNA methylation plays during development, we next asked what happens following implantation, when the processes of differentiation and organogenesis actually begin. One of the first events that occur at this stage is that pluripotency genes, such as Oct4, Nanog and Sox2, get turned off and then remain silenced throughout life in every cell of the body. Using differentiating ES cells as a model system, we found that this silencing takes place in a three-step process (Feldman et al., 2006). Initially, transcription is turned off by trans acting factors. This is followed by binding of the G9a protein that recruits histone deacetylase and then tri-methylates histone H3K9 that consequently binds HP1, thereby heterochromatinizing the gene. Finally, this same G9a recruits the DNA methylases, Dnmt3a and $3 b$, causing de novo methylation (Fig. 8).

These experiments clearly show that methylation represents a late event in the inactivation of pluripotency genes, raising the question of what DNA methylation actually does. To address this issue, we used ES cells to test whether differentiated cells were capable of going back into a pluripotent state. Although WT cells were unable to do this, a large percentage of cells deleted for G9a could recover a pluripotent phenotype when returned to growth in LIF medium, and fine genetic analysis indicated that this was because these cells were not able to recruit the DNA methylases (EpsztejnLitman et al., 2008). It thus appears that de novo methylation does not initiate gene repression, but is necessary for stably keeping a gene in its silenced state.

The fact that G9a is able to recruit DNA methylases shows that there must be a physical link between these two epigenetic mechanisms, histone modification and DNA methylation. It turns out that this relationship is actually part of a general concept in epigenetics, the linking of repression mechanisms (see (Cedar and Bergman, 2009) for review). Thus, it has been shown, for example, that another H3K9 methylase, Suv39h is also able to recruit DNA methylases and this is responsible for DNA methylation of satellite sequences in mammalian cells. The enzyme Ezh2, which methylates H3K27 as part of the polycomb complex, serves 
as a repressor of many developmental genes. It too has the ability to recruit DNA methylases, and it is this process that brings about aberrant de novo methylation in cancer (Schlesinger et al., 2007). Finally, it should be noted that there is a negative relationship between the presence of the activating modification, H3K4me3 and DNA methylation which is based on the idea that this histone modification prevents the recruitment of DNA methylases as occurs during early development (Ooi et al., 2007; Otani etal., 2009). Taken together, these observations suggest that there is an evolutionary connection between histone and DNA-methylation that is built into the structure of the underlying proteins involved in these processes, thus generating a well-designed serial mechanism of repression.

\section{Demethylation}

With this perspective of how the basic methylation pattern is established during early embryogenesis, it became clear that the undermethylation of tissue-specific genes must have come about through a process of demethylation (Fig. 5), but the picture of how this occurs took a long time to decipher. The first hints came from transfection experiments into myoblasts (Yisraeli et al., 1986). In previous studies, in vitro-methylated test genes inserted into fibroblasts were found to show inhibited transcription. When the $\alpha$-actin gene was transfected into muscle cells in culture, however, it was equally active whether or not it had been previously methylated in vitro. Although puzzling at first, it soon became evident that this could be explained by the observation that this gene had actually undergone specific demethylation in these cells. In other words, the inserted exogenous copy of this gene must be recognized by the demethylation machinery in muscle cells and this is what allows it to be expressed, probably in the same manner that the endogenous gene is turned on during normal development. Using reverse genetics, we were able to identify the sequence elements required to direct demethylation and these were located within the 5' regulatory region of the aactin gene (Paroush et al., 1990) (Fig. 9). We later succeeded in deciphering similar elements in the Igk gene region (Lichtenstein et al., 1994), and, in this case, we were also able to show that NFKB may represent the trans-acting protein factor that activates this process (Kirillov et al., 1996). It thus appears that tissue-specific demethylation takes place in a well-ordered preprogrammed manner, with unique elements being able to bind developmental factors designated to recruit the demethylation machinery.

The actual biochemical mechanism of demethylation has long been an enigma. Early workers had suggested that this may occur in a passive manner as a result of DNA replication, simply by blocking the maintenance reaction. While this type of mechanism may contribute to demethylation at early stages of development, many studies have shown that tissue-specific demodification usually occurs in an active manner in the absence of DNA synthesis. This was first demonstrated for the $\delta$-crystallin gene in the eye lens (Sullivan and Grainger, 1986), but was then confirmed in other systems. Using the $\alpha$-actin gene transfected into rat myoblasts, we showed that demethylation even takes place on the original template molecules themselves, clearly indicating that the reaction must be active (Paroush et al., 1990).

It has been very difficult to understand the demethylation reaction, but in retrospect, many facets of this process were already known, although not fully appreciated. Earlier experiments showed quite convincingly that Friend Leukemia cells undergo extensive demethylation when these cells are induced to differentiate and using labeled substrates, it was found that the methylated $\mathrm{C}$ itself is replaced with a new (labeled) Cytosine in this process, suggesting that the reaction does not involve removal of the methyl groups from the base (Razin et al., 1986). This concept was supported by experiments showing that glycosylases could carry out part of this reaction (Jost, 1993; Jost et al., 1995). Finally, studies from our laboratory documented demethylation activity in vitro whereby $5 \mathrm{mC}$ is replaced by cytosine and, by using different labeled substrates, it was possible to show that this replacement involved more than one nucleotide (Weiss et al., 1996; Swisher et al., 1998). Despite these experiments, the full molecular picture of demethylation was still not clear.

The key to understanding demethylation came with the discovery of the Tet family of enzymes that can hydroxylate $5 \mathrm{mC}$ to produce 5hmC (Tahiliani et al., 2009; Ito et al., 2010). This conversion probably represents the first step in the demethylation pathway. According to this idea, the conversion of $5 \mathrm{mC}$ to $5 \mathrm{hmC}$ and further
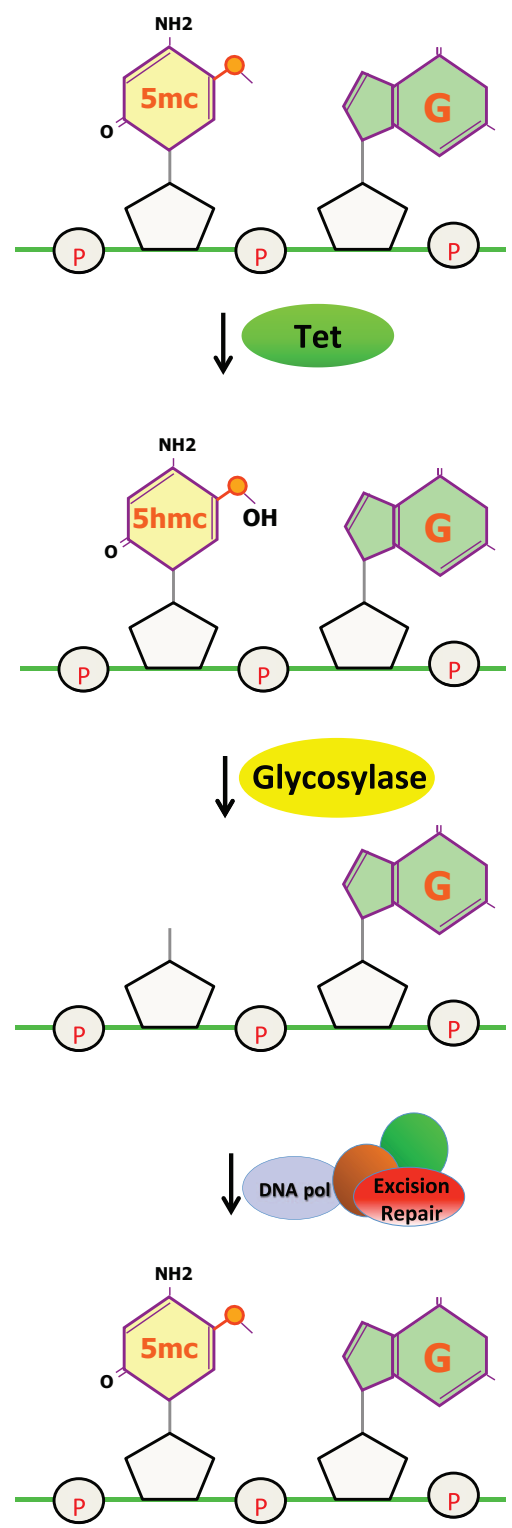

Fig. 10. DNA demethylation pathway. The methylated $C$ residue in the $\mathrm{CPG}$ dinucleotide is hydroxylated by Tet proteins, generating $5 \mathrm{hmC}$. This unusual base can then be removed by a glycosylase generating an apyrimidinic acid residue which may undergo nucleotide excision repair, thereby introducing an unmethylated C. $5 \mathrm{hmC}$ can also be diluted out by replication of the DNA. 
oxidation products $(5 \mathrm{fmC}$ and $5 \mathrm{cmC})$ makes this site into a preferred substrate for glycosylation enzymes that can recognize and remove these bases. This is then followed by a repair process that introduces an unmodified cytosine, thus completing the reaction (Wu and Zhang, 2014) (Fig. 10). The general principle appears to be that $5 \mathrm{mC}$ must be reconfigured to an "unusual" or mismatched base in order for it to be recognized as being "different" so that it can then be removed by the repair machinery or simply diluted out by DNA replication (Guo et al., 2014). In a similar manner there is evidence that the deaminase, AID, may also be involved in demethylation by converting $5 \mathrm{mC}$ to $\mathrm{T}$, which would then be subject to mismatch repair (Dominguez et al., 2015).

Very recently, we were finally able to identify the key molecular components that carry out tissue-specific demethylation and thus provide genetic proof for a two-step pathway. We made a conditional Tet2/Tet3 mouse and generated animals specifically knocked out at the pro-B cell stage of lymphogenesis in vivo. During normal development, B cells go through a process whereby hundreds of regulatory regions undergo demethylation, and this was almost completely prevented in the knockout mouse, clearly indicating that Tet2 and Tet3 are necessary for this process (Orlanski et al., 2016) (Fig. 11). As a result, transcription of many key genes regulated by these enhancers was significantly reduced, greatly inhibiting proper B-cell differentiation and strongly affecting B-cell function in vivo.

Ever since the initial observations indicating that DNAmethylation is inversely correlated with gene expression, there has been much skepticism about the role of this modification, with many scientists claiming that all gene regulation is mediated exclusively by transacting factors and that DNA methylation does not really play any
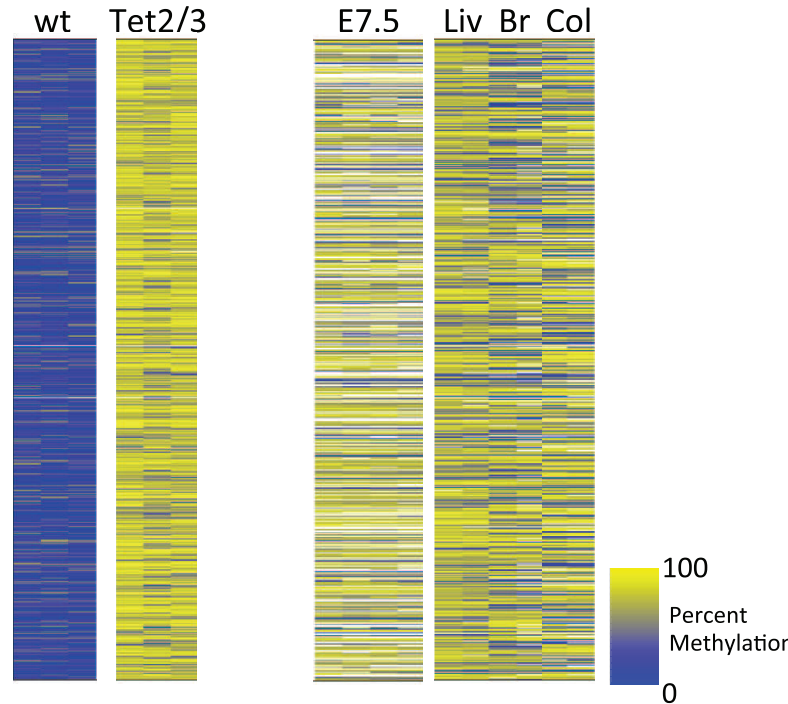

role, other than serving to mark inactive genes (Ptashne, 2007). Although there have been a number of good artificial experiments showing that DNA methylation inhibits gene expression both in vitro and in vivo, definitive proof for this idea was lacking, mainly because there was no way to specifically inhibit demethylation without affecting other factors involved in the regulatory process. Since Tet enzymes appear to be only capable of carrying out the biochemical aspects of this process, the experiment described above using a Tet2/Tet3 knockout in B cells represents the first real proof for the role of methylation in gene regulation. Thus, even though all the proper trans-acting factors are still readily available during B-cell development in the knockout, programmed gene activation cannot take place, simply because the methyl groups are still present, somehow preventing proper transcription of adjacent genes.

\section{DNA methylation in cancer}

Cancer cells have an altered methylation pattern, with many regions showing hypomethylation while others, in particular $\mathrm{CpG}$

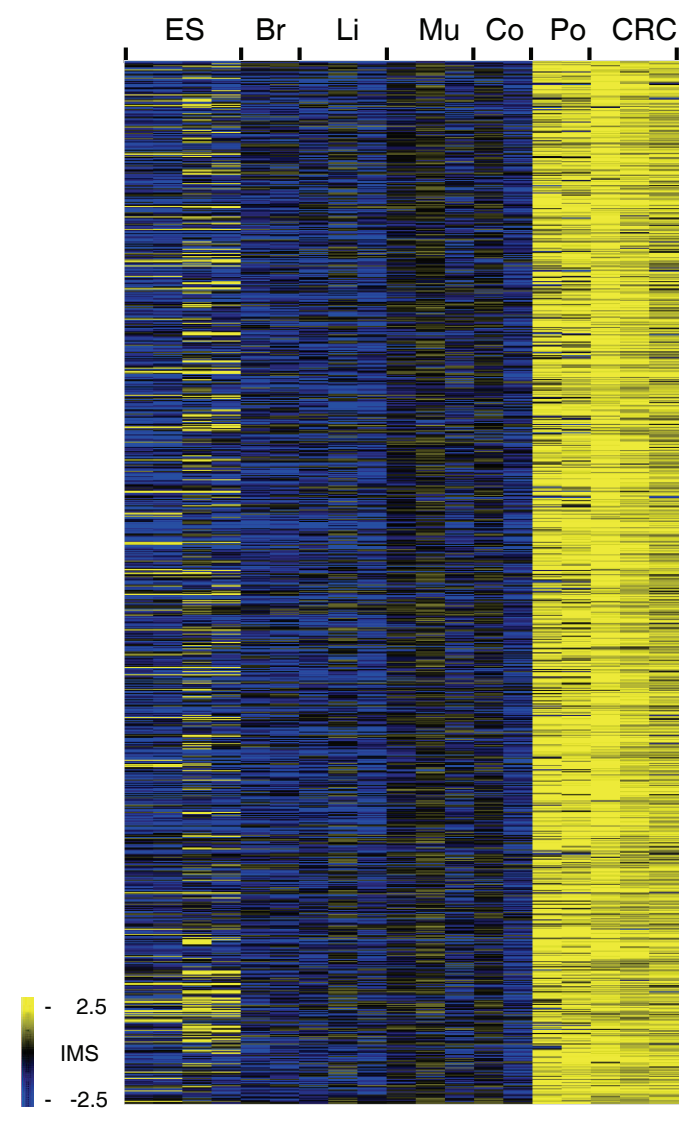

Fig. 11 (Left). Tet mediates tissue-specific methylation. The heat map shows methylation analysis (yellow, methylated; blue, unmethylated) of 1,400 tiles (100 bp) that undergo demethylation specifically in follicular B cells. These sequences are methylated in the embryo (E $7.5 \mathrm{~d}$ ) right after implantation and remain methylated in all tissues (e.g. liver, brain, colon). They are hypo-methylated in wt B-cells. Knockout of Tet2 and Tet3 at an early stage of $B$-cell development prevents this demethylation. These tiles are mainly nearby enhancers of B-cell specific genes and preventing demethylation inhibits the activation of these genes. Adapted from (Orlanski et al., 2016).

Fig. 12 (Right). Aberrant methylation in cancer. Heatmap showing methylation analysis (yellow, methylated; blue, unmethylated) of 2,000 CpG islands that are aberrantly methylated in colon cancer (CRC) as compared to normal tissues (ES cells, brain, liver, muscle, colon). Almost all of these islands are bound by the polycomb complex. Note that these islands are already highly methylated in colon polyps (Po), a benign tumor that precedes cancer. Adapted from (Nejman et al., 2013). 
islands, become de novo methylated compared to normal cells of the same tissue type (Baylin and Jones, 2011). Initially, it was thought that these changes represented an alternative pathway towards affecting "cancer genes," with de novo methylation turning off tumor suppressors, while demethylation serving to turn on normally-silenced oncogenes. It turned out, however, that this represented an oversimplified view of the role of DNA methylation in cancer. Further studies have now clarified, to some extent, how methylation is altered in cancer and how this affects tumor biology.

As a first step in this direction, microarray technology revealed that a large number of $\mathrm{CpG}$ islands actually undergo de novo methylation, including many that are not associated with tumor suppressor genes (Keshet et al., 2006) (Fig. 12). This observation implied that this de novo process was not driven by selection, but rather was taking place as a result of an instructive mechanism. Further studies demonstrated that almost all of these methylation events occur at $\mathrm{CpG}$ islands that are bound by polycomb (Schlesinger et al., 2007). This complex is a repressor that works by virtue of the enzyme EZH2 to methylate histone H3 Lysine 27 on local nucleosomes, thereby bringing about a state of local heterochromatin. This represents a general system for silencing almost all the key developmental and differentiation genes in the cell from the time of early embryogenesis. This polycomb-mediated repression dos not normally involve DNA methylation and occurs exclusively on promoter and regulatory sequences that have $\mathrm{CpG}$ islands and are therefore constitutively unmethylated.

In cancer, these sites appear to undergo de novo methylation (Nejman et al., 2013). Although the trigger for this is not known, it is probably carried out by the enzyme EZH2 itself, which, in addition to its activity as a histone methylase, can also bind DMNT3, thus exposing these sites to DNA methylation (Vire et al., 2006). Earlier studies had noted that many of the sites aberrantly methylated in tumors are found to be slightly methylated in normal tissues, as well, in a manner that appears to increase with age (Teschendorff et al., 2010; Issa, 2014; Kulis et al., 2015) and it turns out that these patterns are actually very similar in all cell types with the degree of methylation at each locus apparently controlled by the level of bound polycomb (Nejman et al., 2013). In addition to de novo methylation at $\mathrm{CpG}$ islands, it was originally noted that tumors are also characterized by widespread hypomethylation and this evidently comes about as a result of demethylation at regions associated with the nuclear lamina covering over $40 \%$ of the genome (Berman et al., 2012). These observations have now been elegantly confirmed by genome-wide studies showing the changes in methylation that take place in hematopoietic or skin stem cells during aging in vivo (Raddatz et al., 2013; Sun et al., 2014).

These wide-ranging experiments have put together an interesting picture of how DNA methylation may be involved in tumorigenesis. Firstly, it should be noted that the methylation pattern observed in tumor cells might already exist in the normal cell population. Analysis of individual DNA molecules in normal tissues carried out in our laboratory indicates that for any particular island, almost all molecules are completely unmethylated, with only a few being highly modified. This suggests that the aberrant methylation pattern may actually be present at relatively high levels, but only in select cells (Nejman et al., 2013). We would propose that it is these cells that are prone to cancer.

According to the original concept that aberrant DNA methylation in cancer cells operates to inactivate tumor suppresser genes, it
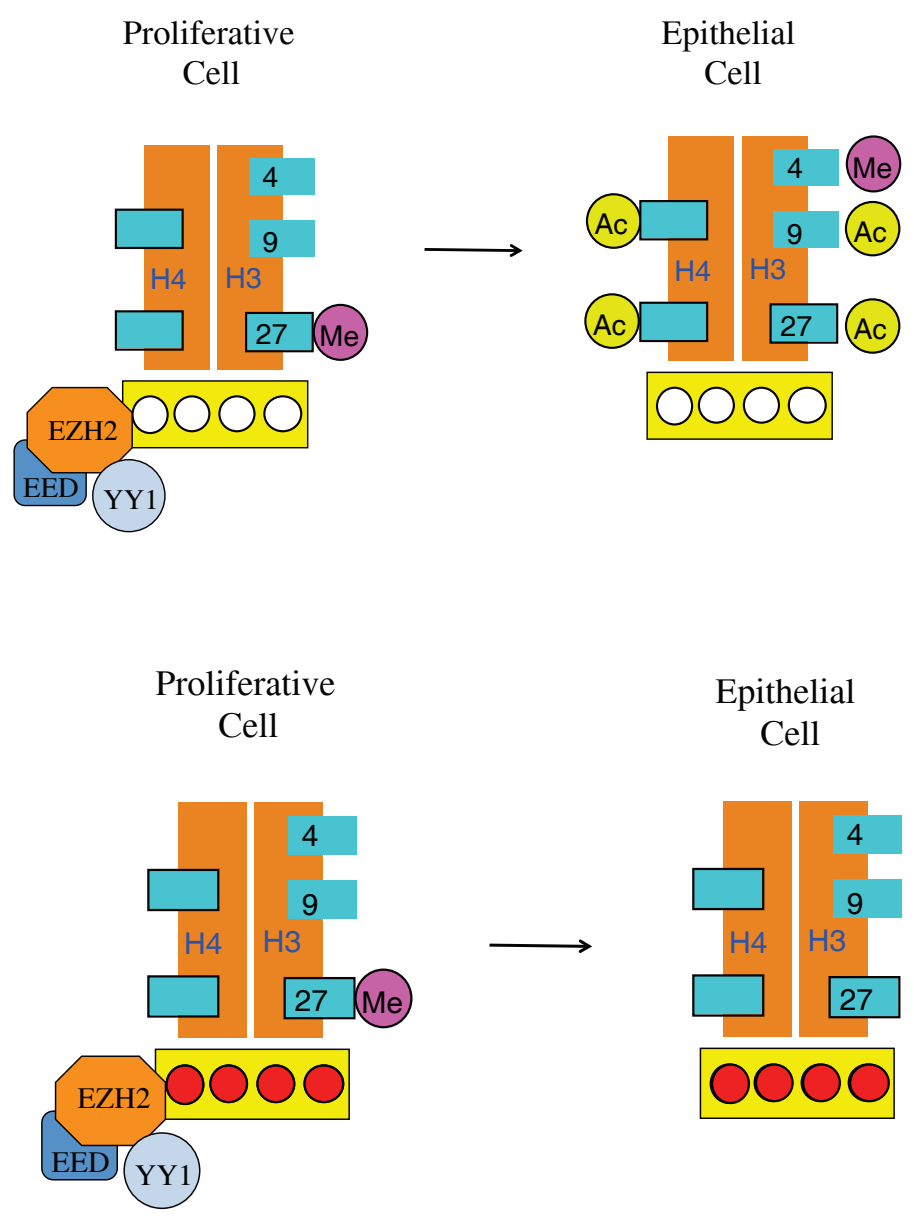

Fig. 13. Effect of DNA methylation in colon tumorigenesis. Normal colon epithelium is derived from numerous crypts which contain stem cells that constantly generate proliferative progenitor cells. These climb up the crypt and at some point undergo differentiation to mature epithelial cells. In normal proliferative cells of the colon (top), polycomb-target genes are repressed by the presence of a repressive complex, which contains the histone methyltransferase EZH2 and other proteins. Although the expression of these genes is inhibited, most of them have unmethylated (white circles) CpG island promoters and therefore maintain the potential for being activated (note acetylation of histones) during differentiation to epithelium. Cancer may initiate in stem cells in which polycomb target genes have already become de novo methylated (red circles) during aging. Although these genes are able to shed their polycomb complex as the cells advance up the crypt, they are prevented from being activated during differentiation because they are stably DNA methylated.

was assumed that the pattern of modification in the tumor brings about repression of genes that were initially active in the normal tissue. RNA analyses, however, demonstrated that this is not really the case. Rather, over $90 \%$ of the target genes were found to be inactive even prior to tumorigenesis (Keshet et al., 2006), and this is in keeping with our findings that these genes are marked by polycomb. In light of this, we proposed that while mutations are essential to initiate the transformation process, the high level of aberrant methylation in target cells could be needed for the tumor to expand. This may happen because the presence of methyl groups on key developmental genes could prevent them from undergoing proper differentiation, thereby leaving them in a relatively prolifera- 
tive state (Fig. 13). Alternatively, this pre-existing methylation may prevent the activation of many repair and apoptosis genes that the cell would normally use to prevent tumorigenesis.

This model is consistent with everything we know about the basic biology of DNA methylation. In every instance of site-specific de novo methylation, the initial repression itself always takes place through the involvement of repression factors, with DNA methylation coming as a secondary mechanism to provide long-term silencing stability. Indeed, even the initial global methylation at the time of implantation only takes place at sites that are already inactive. Thus, while DNA methylation, itself, cannot directly cause gene repression once this modification occurs it becomes very difficult to activate the underlying gene without removing the methyl groups.

\section{Postnatal changes in DNA methylation}

While it is well accepted that DNA methylation patterns are established during development, one of the major questions in epigenetics is whether further changes can occur postnatally and whether these may be brought about through the influence of environment. As a first step in approaching this problem, we asked whether there may be differences in methylation between males and females that appear post adolescence when sex hormones beginning to be secreted (Reizel et al., 2015). We used a genome-wide assay (RRBS) to analyze DNA from mouse liver at various times after birth into adulthood. In a striking manner, we observed hundreds of differences in DNA methylation with almost all of them being hypomethylated in the male. These differentially methylated regions (DMRs) are formed starting at about three weeks of age by a process of demethylation and are programmed to occur at enhancer-like sequences associated with liver genes



Fig. 14. Testosterone activates genes through demethylation. A large number of gene promoters (red) are controlled by enhancers (blue) in the liver. These genes have low expression profiles at one week of age, but get promoter (red) activated postnatally and are highly expressed at $20 \mathrm{wk}$ of age after testosterone brings about demethylation at the enhancer. In castrated animals (C), there is no testosterone, so the gene does not get activated. Castration late in life removes the testosterone after the enhancer has already undergone demethylation, but the liver retains a memory (undermethylation) and therefore expresses this gene at a slightly lower level. specifically activated in the male, but not the female. This entire process appears to occur as a result of testosterone secretion and in its absence male specific gene expression is not seen (Fig. 14). Furthermore, treatment of females with this hormone can also induce these changes. These results indicate that postnatal methylation changes can occur in a programmed manner directed by trans acting protein factors.

Recent studies in our laboratory have demonstrated that postnatal demethylation is very prevalent in the mouse and in humans, with thousands of enhancer-like sequences becoming hypomethylated in a variety of different tissue types during the first few weeks of life and these have a wide-ranging effect on specific gene expression in these tissues. Preliminary experiments using a Tet2/Tet3 knockout approach show that these changes are essential for normal expression. It is clear that these demethylation events must be driven by the appearance of hormone-like substances, growth factors or metabolites. Many of these alterations occur in the brain. It thus appears that tissues of the body undergo adaptive changes presumably in response to internal influences. In the same manner, it seems likely that outside influences from the environment could trigger the release of internal hormonal-like substances that could then set in motion a programmed process of methylation changes that may first have an immediate effect on tissue metabolism but then remain this way in a stable manner. Any changes in methylation that occur would undoubtedly be "remembered" as a result of the ability of DNA methylation to be maintained for long periods of time even after the original inducer is no longer present.

\section{Conclusions}

When we first started working on DNA methylation, the main focus of molecular biology was to decipher the genetic text and understand how this book of instructions is used to generate an organism and navigate its biology. As the methylation story emerged, it has become clear that this epigenetic marker plays a key role in controlling how the DNA text is actually used and interpreted, especially in long-living eukaryotic organisms like man. In a sense, we have learned that the DNA, much like other languages, has a system of annotation, with methylation being the main player. Our studies have also revealed a brand new regulatory mechanism. Unlike classical repression brought about by trans acting factors that are plastic in nature, DNA methylation produces a permanent state of gene silencing which can be maintained for many years, even in dividing cells. This same modification can also serve as a memory mechanism for propagating decisions made at earlier stages of development.

This research has opened up exciting new vistas. Understanding how methylation works in development has many implications for health and disease. Fragile $X$ syndrome, for example, is a developmental disease in which a single gene is abnormally turned off by DNA methylation. Because the gene itself is intact, however, there is a distinct possibility that this disease can actually be prevented or reversed by demethylation agents such as $5 a z a C$. Similarly, $5 a z a C$ may be able to derepress the $\gamma$-globin gene in red blood cells of patients with $\beta$-Thalassemia, thereby bypassing the defect. Our knowledge of the role of DNA methylation in cancer has spurred clinical research aimed at using demethylating agents to treat a variety of different tumors, and this approach may even provide 
a new route to prevention (Laird et al., 1995). Finally, it should be noted that DNA methylation can serve as a potent diagnostic tool as well. Recent studies done in collaboration with Yuval Dor and Ruth Shemer (Lehmann-Werman et al., 2016) show that DNA methylation profiles can be used to identify the tissue origin of free circulating DNA in plasma, thus providing an exciting new way to detect cell death derived from specific cell types in the body. Using this approach, it may now be possible to employ periodic blood tests to pick up signs of disease, leading the way to the early diagnosis of Type I diabetes, multiple sclerosis, myocardial infarction, sports-induced chronic traumatic encephalopathy (CTE), and other pathologic processes characterized by cell death.

The main challenge of DNA methylation research in the future is to understand the possible role of DNA methylation as a memory mechanism for the effect of environmentongene expression. There is strong circumstantial evidence that what we eat, exposure to different surroundings and life-changing events may all bring about long-term changes in body function, and there is strong suspicion that this may be mediated by DNA methylation. Even more exciting is the possibility that environmentally-induced epigenetic changes that occur in the parent may be "inherited" by the offspring as a shortcut to evolution, and here too, this might involve some form of DNA-methylation-derived memory.

\section{References}

AXEL R, CEDAR H, FELSENFELD G (1973). The synthesis of globin RNA from duck reticulocyte chromatin in vitro. Proc Natl Acad Sci USA 70: 20292032.

BAYLIN S B, JONES PA (2011). A decade of exploring the cancer epigenome biological and translational implications. Nature Rev Cancer 11: 726-734.

BERMAN B P, WEISENBERGER D J, AMAN J F, HINOUE T, RAMJAN Z, LIU Y, NOUSHMEHR H, LANGE C P, VAN DIJK C M, TOLLENAAR RA et al., (2012). Regions of focal DNA hypermethylation and long-range hypomethylation in colorectal cancer coincide with nuclear lamina-associated domains. Nature Genet44: 40-46.

BIRGER Y, SHEMER R, PERK J, RAZIN A (1999). The imprinting box of the mouse Igf2r gene. Nature 397: 84-88.

BOSTICK M, KIM J K, ESTEVE P O, CLARK A, PRADHAN S, JACOBSEN S E (2007). UHRF1 plays a role in maintaining DNA methylation in mammalian cells. Science 317: 1760-1764.

BRANDEIS M, FRANK D, KESHET I, SIEGFRIED Z, MENDELSOHN M, NEMES A, TEMPER V, RAZIN A, CEDAR H (1994). Sp1 elements protect a CpG island from de novo methylation. Nature 371: 435-438.

BRANDEIS M, KAFRI T, ARIEL M, CHAILLET J R, MCCARREY J, RAZIN A, CEDAR $H$ (1993). The ontogeny of allele-specific methylation associated with imprinted genes in the mouse. EMBO J 12: 3669-3677.

CEDAR H, BERGMAN Y (2009). Linking DNA methylation and histone modification: patterns and paradigms. Nature Rev Genet 10: 295-304.

CEDAR H, BERGMAN Y (2012). Programming of DNA Methylation Patterns. Annu Rev Biochem 81: 97-117.

CEDAR H, FELSENFELD G (1973). Transcription of chromatin in vitro. J Mol Biol 77: 237-254.

CEDAR H, SOlAGE A, GLASER G, RAZIN A (1979). Direct detection of methylated cytosine in DNA by use of the restriction enzyme Mspl. Nucleic Acids Res 6: 2125-2132

DOMINGUEZ P M, TEATER M, CHAMBWE N, KORMAKSSON M, REDMOND D, ISHII J, VUONG B, CHAUDHURI J, MELNICK A, VASANTHAKUMAR A et al., (2015). DNA Methylation Dynamics of Germinal Center B Cells Are Mediated by AID. Cell reports 12: 2086-2098.

EDEN S, HASHIMSHONY T, KESHET I, THORNE A W, CEDAR H (1998). DNA methylation models histone acetylation. Nature 394: 842-843.

EPSZTEJN-LITMAN S, FELDMAN N, ABU-REMAILEH M, SHUFARO Y, GERSON A, UEDA J, DEPLUS R, FUKS F, SHINKAI Y, CEDAR H et al., (2008). De novo
DNA methylation promoted by G9a prevents reprogramming of embryonically silenced genes. Nature Struct Mol Biol 15: 1176-1183.

FELDMAN N, GERSON A, FANG J, LI E, ZHANG Y, SHINKAI Y, CEDAR H, BERGMANY (2006). G9a-mediated irreversible epigenetic inactivation of Oct-3/4 during early embryogenesis. Nature Cell Biol 8: 188-194.

FELSENFELD G (1978). Chromatin. Nature 271: 115-122.

FRANK D, KESHET I, SHANI M, LEVINE A, RAZIN A, CEDAR H (1991). Demethylation of $\mathrm{CpG}$ islands in embryonic cells. Nature 351: 239-241.

GOREN A, SIMCHEN G, FIBACH E, SZABO P E, TANIMOTO K, CHAKALOVA L, PFEIFER G P, FRASER P J, ENGEL J D, CEDAR H (2006). Fine Tuning of Globin Gene Expression by DNA Methylation. PLOS ONE 1: e46.

GRUENBAUM Y, CEDAR H, RAZIN A (1982). Substrate and sequence specificity of a eukaryotic DNA methylase. Nature 295: 620-622.

GRUENBAUM Y, NAVEH-MANY T, CEDAR H, RAZINA (1981). Sequence specificity of methylation in higher plant DNA. Nature 292: 860-862.

GUOF, LIX, LIANG D, LI T, ZHUP, GUOH, WU X, WENL, GU TP, HU B et al., (2014). Active and passive demethylation of male and female pronuclear DNA in the mammalian zygote. Cell Stem Cell 15: 447-458.

HASHIMSHONY T, ZHANG J, KESHET I, BUSTIN M, CEDAR H (2003). The role of DNA methylation in setting up chromatin structure during development. Nature Genet 34: 187-192.

ISSA J P (2014). Aging and epigenetic drift: a vicious cycle. J Clin Invest 124: 24-29.

ITO S, D'ALESSIO A C, TARANOVA O V, HONG K, SOWERS L C, ZHANG Y (2010). Role of Tet proteins in $5 \mathrm{mC}$ to $5 \mathrm{hmC}$ conversion, ES-cell self-renewal and inner cell mass specification. Nature 466: 1129-1133.

JOST J P (1993). Nuclear extracts of chicken embryos promote an active demethylation of DNA by excision repair of 5-methyldeoxycytidine. Proc Natl Acad Sci USA 90: 4684-4688.

JOST JP, SIEGMANN M, SUN L, LEUNG R (1995). Mechanism of DNAdemethylation in chicken embryos. J Biol Chem 370: 9734-9739.

KAFRI T, ARIEL M, BRANDEIS M, SHEMER R, URVEN L, MCCARREY J, CEDAR $H$, RAZIN A (1992). Developmental pattern of gene-specific DNA methylation in the mouse embryo and germline. Genes Dev. 6: 705-714.

KAFRIT, GAOX, RAZINA(1993). Mechanistic aspects of genome-wide demethylation in the preimplantation mouse embryo. Proc Natl Acad Sci USA 90: 10558-10562.

KESHET I, LIEMAN-HURWITZ J, CEDAR H (1986). DNA methylation affects the formation of active chromatin. Cell 44: 535-543.

KESHETI, SCHLESINGERY, FARKASHS, RAND E, HECHTM, SEGALE, PIKARSKI E, YOUNG RA, NIVELEAU A, CEDAR H et al., (2006). Evidence for an instructive mechanism of de novo methylation in cancer cells. Nature Genet 38: 149-153.

KIRILLOV A, KISTLER B, MOSTOSLAVSKY R, CEDAR H, WIRTH T, BERGMAN Y (1996). A role for nuclear NF-kB in B-cell-specific demethylation of the lgk locus. Nature Genet 13: 435-441.

KULIS M, MERKEL A, HEATH S, QUEIROS A C, SCHUYLER R P, CASTELLANO G, BEEKMAN R, RAINERI E, ESTEVE A, CLOT G et al., (2015). Whole-genome fingerprint of the DNA methylome during human B cell differentiation. Nature Genet 47: 746-756.

LAIRD P W, JACKSON-GRUSBY L, FAZELI A, DICKINSON S L, JUNG W E, LI E, WEINBERG R A, JAENISCH R (1995). Suppression of intestinal neoplasia by DNA hypomethylation. Cell 81: 197-205.

LEHMANN-WERMAN R, NEIMAN D, ZEMMOUR H, MOSS J, MAGENHEIM J, VAKNINDEMBINSKY A, RUBERTSSON S, NELLGARD B, BLENNOW $K$ ZETTERBERG $\mathrm{H}$ et al., (2016). Identification of tissue-specific cell death using methylation patterns of circulating DNA. ProcNatIAcad SciUSA113: E1826-1834.

LI E, BEARD C, JAENISCH R (1993). Role for DNA methylation in genomic imprinting. Nature 366: 362-365.

LICHTENSTEIN M, KEINI G, CEDAR H, BERGMANY (1994). B-cell specific demethylation: a novel role for the intronic k-chain enhancer sequence. Cell 76: 913-923.

MONK M, BOUBELIK M, LEHNERT S (1987). Temporal and regional changes in DNA methylation in the embryonic, extraembryonic and germ cell lineages during mouse embryo development. Development 99: 371-382.

NAVEH-MANY T, CEDAR H (1981). Active gene sequences are undermethylated Proc Natl Acad Sci USA 78: 4246-4250.

NEJMAN D, STRAUSSMAN R, STEINFELD I, RUVOLO M, ROBERTS D, YAKHINI 
Z, CEDAR H (2013). Molecular rules governing de novo methylation in cancer. Cancer Res 74: 1475-1483.

OOI S K, QIU C, BERNSTEIN E, LI K, JIA D, YANG Z, ERDJUMENT-BROMAGE H, TEMPST P, LIN S P, ALLIS C D et al., (2007). DNMT3L connects unmethylated lysine 4 of histone $\mathrm{H} 3$ to de novo methylation of DNA. Nature 448: 714-717.

ORLANSKI S, LABI V, REIZEL Y, SPIRO A, LICHTENSTEIN M, LEVIN-KLEIN R, KORALOVS, SKVERSKYY, RJEWSKYK, CEDAR H etal., (2016). Tissue-specific DNA demethylation is required for proper B-cell differentiation and function. Proc Natl Acad Sci USA 113: 5018-5023.

OTANI J, NANKUMO T, ARITA K, INAMOTO S, ARIYOSHI M, SHIRAKAWA M (2009). Structural basis for recognition of H3K4 methylation status by the DNA methyltransferase 3AATRX-DNMT3-DNMT3Ldomain. EMBO Rep10:1235-1241.

PANET A, CEDAR H (1977). Selective degradation of integrated murine leukemia proviral DNA by deoxyribonucleases. Cell 11: 933-940.

PAROUSH Z, KESHET I, YISRAELI J, CEDAR H (1990). Dynamics of demethylation and activation of the a actin gene in myoblasts. Cell 63: 1229-1237.

PERK J, MAKEDONSKI K, LANDE L, CEDAR H, RAZIN A, SHEMER R (2002). The imprinting mechanism of the Prader-Willi/Angelman regional control center. EMBO J 21: 5807-5814.

POLLACK Y, STEIN R, RAZIN A, CEDAR H (1980). Methylation of foreign DNA sequences in eukaryotic cells. Proc Natl Acad Sci USA 77: 6463-6467.

PTASHNE M (2007). On the use of the word 'epigenetic'. Curr Biol 17: R233R236.

RADDATZ G, HAGEMANN S, ARAN D, SOHLE J, KULKARNI P P, KADERALI L, HELLMAN A, WINNEFELD M, LYKO F (2013). Aging is associated with highly defined epigenetic changes in the human epidermis. Epigenetics Chromatin 6:36.

RAZIN A, CEDAR H (1977). Distribution of 5-methylcytosine in chromatin. Proc Natl Acad Sci USA 74: 2725-2728.

RAZINA, RIGGSAD (1980). DNAmethylation and gene function. Science210:604-610.

RAZIN A, SZYF M, KAFRI T, ROLL M, GILOH H, SCARPA S, CAROTTI D, CANTONI $\mathrm{G} \mathrm{L}$ (1986). Replacement or 5-methylcytosine by cytosine: a possible mechanism for transient DNA demethylation during differentiation. Proc Natl Acad Sci USA 83: $2827-2831$

REIZEL Y, SPIRO A, SABAG O, SKVERSKYY, HECHT M, KESHETI, BERMAN B-P, CEDAR H (2015). Gender-specific postnatal demethylation and establishment of epigenetic memory. Genes Dev. 29: 923-933.

SABAG O, ZAMIR A, KESHET I, HECHT M, LUDWIG G, TABIB A, MOSS J, CEDAR $\mathrm{H}$ (2014). Establishment of methylation patterns in ES cells. Nature Struct $\mathrm{Mol}$ Biol 21: 110-112.

SCHLESINGER Y, STRAUSSMAN R, KESHET I, FARKASH S, HECHT M, ZIMMERMAN J, EDEN E, YAKHINI Z, BEN-SHUSHAN E, REUBINOFF B E et al., (2007). Polycomb mediated histone $\mathrm{H} 3(\mathrm{~K} 27)$ methylation pre-marks genes for de novo methylation in cancer. Nature Genet 39: 232-236.

SHEMER R, HERSHKO A Y, PERK J, MOSTOSLAVSKY R, TSUBERI B-Z, CEDAR $\mathrm{H}$, BUITING K, RAZIN A (2000). The imprinting box of the PraderWilli/Angelman Syndrome domain. Nature Genet 26: 440-443.

SIEGFRIED Z, CEDAR H (1997). DNA methylation: A molecular lock. Curr Biol 7: 305-307.

SMITHZD, CHAN M M, HUMM KC, KARNIKR, MEKHOUBAD S, REGEV A, EGGAN K, MEISSNERA(2014). DNA methylation dynamics of the human preimplantation embryo. Nature 511: 611-615.

SMITH ZD, CHAN M M, MIKKELSEN TS, GU H, GNIRKE A, REGEV A, MEISSNER
A (2012). A unique regulatory phase of DNA methylation in the early mammalian embryo. Nature 484: 339-344.

SOLAGE A, CEDAR H (1978). Organization of 5-methylcytosine in chromosomal DNA. Biochemistry 17: 2934-2938.

STEIN R, GRUENBAUM Y, POLLACK Y, RAZIN A, CEDAR H (1982a). Clonal inheritance of the pattern DNA methylation in mouse cells. Proc Natl Acad Sci USA 79: 61-65.

STEIN R, RAZIN A, CEDARH (1982b). In vitro methylation of the hamster APRT gene inhibits its expression in mouse L-cells. Proc Natl Acad Sci USA 79: 3418-3422.

STOGER R, KUBICKA P, LIU C-G, KAFRI T, RAZIN A, CEDAR H, BARLOW D P (1993). Maternal-specific methylation of the imprinted mouse lgf2r locus identifies the expressed locus as carrying the imprinting signal. Cell 73: 61-71.

STRAUSSMAN R, NEJMAN D, ROBERTS D, STEINFELD I, BLUM B, BENVENISTY N, SIMON I, YAKHINI Z, CEDAR H (2009). Developmental programming of CpG island methylation profiles in the human genome. Nature StructMolBiol16:564-571.

SULLIVAN C H, GRAINGER R M (1986). d-Crystallin genes become hypomethylated in postmitotic lens cells during chicken development. Proc Natl Acad Sci USA 83: 329-333.

SUN D, LUO M, JEONG M, RODRIGUEZ B, XIA Z, HANNAH R, WANG H, LE T, FAULL K F, CHEN R et al., (2014). Epigenomic Profiling of Young and Aged HSCs Reveals Concerted Changes during Aging that Reinforce Self-Renewal. Cell Stem Cell 14: 673-688.

SWISHER J F, RAND E, CEDAR H, PYLE A M (1998). Analysis of putative RNase sensitivity and protease insensitivity of demethylation activity in extracts from rat myoblasts. Nucleic Acids Res 26: 5573-5580.

TAHILIANI M, KOH K P, SHEN Y, PASTOR W A, BANDUKWALA H, BRUDNO Y, AGARWAL S, IYER L M, LIU D R, ARAVIND L et al., (2009). Conversion of 5methylcytosine to 5-hydroxymethylcytosine in mammalian DNA by MLL partner TET1. Science 324: 930-935.

TESCHENDORFF A E, MENON U, GENTRY-MAHARAJ A, RAMUS S J, WEISENBERGER D J, SHEN H, CAMPAN M, NOUSHMEHR H, BELL C G, MAXWELL A $P$ et al., (2010). Age-dependent DNA methylation of genes that are suppressed in stem cells is a hallmark of cancer. Genome Res 20: 440-446.

VAN DER PLOEG LHT, FLAVELL RA (1980). DNA methylation in the human gamma delta beta-globin locus in erythroid and nonerythroid tissues. Cell 19: 947-958.

VIRE E, BRENNER C, DEPLUS R, BLANCHON L, FRAGA M, DIDELOT C, MOREY L, VAN EYNDE A, BERNARD D, VANDERWINDEN J M et al., (2006). The Polycomb group protein EZH2 directly controls DNAmethylation. Nature 439:871-874.

WEINTRAUB H, GROUDINE M (1976). Chromosomal subunits in active genes have an altered conformation. Science 193: 848-856.

WEISS A, KESHET I, RAZIN A, CEDAR H (1996). DNA demethylation in vitro: Involvement of RNA. Cell 86: 709-718.

WIGLER M, SILVERSTEIN S, LEE L S, PELLICER A, CHENG Y, AXEL R (1977). Transfer of purified herpes virus thymidine kinase gene to cultured mouse cells. Cell 11: 223-232.

WU H, ZHANG Y (2014). Reversing DNA methylation: mechanisms, genomics, and biological functions. Cell 156: 45-68.

YISRAELI J, ADELSTEIN R S, MELLOUL D, NUDEL U, YAFFE D, CEDAR H (1986). Muscle-specific activation of a methylated chimeric actin gene. Cell 46: 409-416.

YISRAELI J, FRANK D, RAZIN A, CEDAR H (1988). Effect of in vitro DNA methylation on beta globin gene expression. Proc Natl Acad Sci USA 85: 4638-4642. 
Further Related Reading, published previously in the Int. J. Dev. Biol.

Epigenetics and imprinting in human disease

Jennifer M. Kalish, Connie Jiang and Marisa S. Bartolomei

Int. J. Dev. Biol. (2014) 58: 291-298

DNA methylation and its role in the trophoblast cell lineage Satoshi Tanaka, Momo O. Nakanishi and Kunio Shiota

Int. J. Dev. Biol. (2014) 58: 231-238

DNA methylation establishment during oocyte growth: mechanisms and significance Shin-Ichi Tomizawa, Joanna Nowacka-Woszuk and Gavin Kelsey Int. J. Dev. Biol. (2012) 56: 867-875

DNA methylation reprogramming and DNA repair in the mouse zygote Konstantin Lepikhov, Mark Wossidlo, Julia Arand and Jörn Walter Int. J. Dev. Biol. (2010) 54: 1565-1574

Epigenetic asymmetry in the zygote and mammalian development Robert Feil

Int. J. Dev. Biol. (2009) 53: 191-201
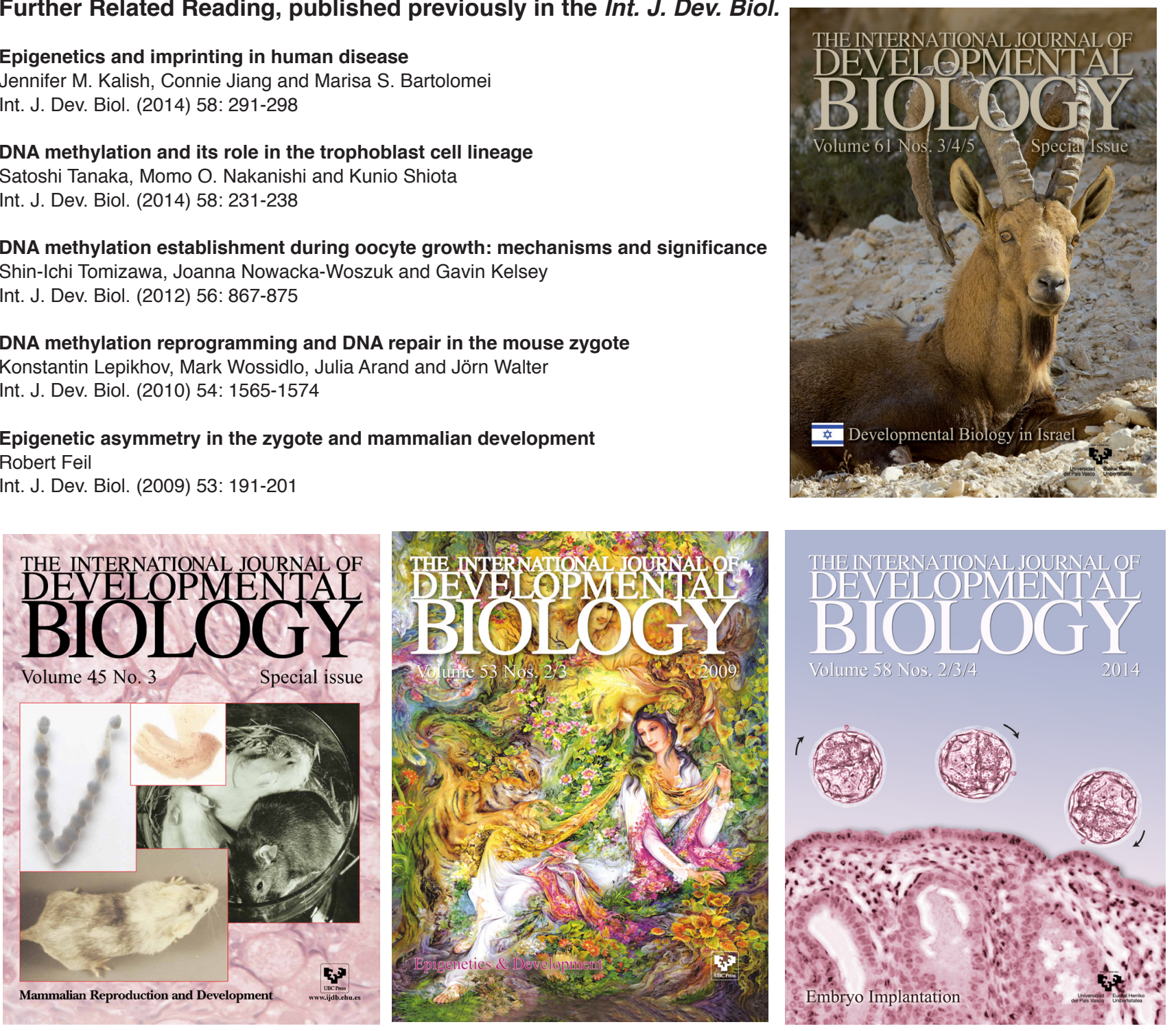